\title{
The prostanoid pathway contains potential prognostic markers for glioblastoma
}

DOI:

10.1016/j.prostaglandins.2018.06.003

\section{Document Version}

Accepted author manuscript

Link to publication record in Manchester Research Explorer

\section{Citation for published version (APA):}

Nicolaou, A., Panagopoulos, A. T., Gomes, R. N., Almeida, F. G., da Costa Souza, F., Veiga, J. C. E., \& Colquhoun, A. (2018). The prostanoid pathway contains potential prognostic markers for glioblastoma.

Prostaglandins and Other Lipid Mediators, 137, 52. [137]. https://doi.org/10.1016/j.prostaglandins.2018.06.003

\section{Published in:}

Prostaglandins and Other Lipid Mediators

\section{Citing this paper}

Please note that where the full-text provided on Manchester Research Explorer is the Author Accepted Manuscript or Proof version this may differ from the final Published version. If citing, it is advised that you check and use the publisher's definitive version.

\section{General rights}

Copyright and moral rights for the publications made accessible in the Research Explorer are retained by the authors and/or other copyright owners and it is a condition of accessing publications that users recognise and abide by the legal requirements associated with these rights.

\section{Takedown policy}

If you believe that this document breaches copyright please refer to the University of Manchester's Takedown Procedures [http://man.ac.uk/04Y6Bo] or contact uml.scholarlycommunications@manchester.ac.uk providing relevant details, so we can investigate your claim.

\section{OPEN ACCESS}


The prostanoid pathway contains potential prognostic markers for glioblastoma

Alexandros Theodoros Panagopoulos, Renata Nascimento Gomes, Fernando Gonçalves Almeida, Felipe da Costa Souza, José Carlos Esteves Veiga, Anna Nicolaou, Alison Colquhoun.

Department of Neurosurgery, Santa Casa Hospital, São Paulo, Brazil (ATP, JCEV)

Department of Cell and Developmental Biology, Biomedical Sciences Institute, University of São Paulo, São Paulo, Brazil (RNG, FCS, AC)

CEFAP, Biomedical Sciences Institute, University of São Paulo, São Paulo, Brazil (FGA)

Division of Pharmacy and Optometry, School of Health Sciences, Faculty of Biology Medicine and Health, The University of Manchester, UK (AN)

Running title: Prostanoids in gliomas

Corresponding author: Alison Colquhoun, D.Phil. (Oxon), Department of Cell and Developmental Biology, Biomedical Sciences Institute, University of São Paulo, Avenida Professor Lineu Prestes 1524, Butantã, 05508-000, São Paulo, SP, Brazil.

Tel: 551130917261 Email: alison@usp.br

Footnotes: ATP and RNG are joint first authors with equal contribution to the study.

Funding: The research was funded by FAPESP (10/51999-0, 15/08777-0), CNPq and CAPES.

Conflict of interests: None 


\section{Abstract}

Prostanoids derived from the activity of cyclooxygenases and their respective synthases contribute to both active inflammation and immune response in the tumor microenvironment. Their synthesis, deactivation and role in glioma biology have not yet been fully explored and require further study. Using quantitative real time PCR, gas chromatography/ electron impact mass spectrometry and liquid chromatography/ electrospray ionization tandem mass spectrometry, we have further characterized the prostanoid pathway in grade IV glioblastoma (GBM). We observed significant correlations between high mRNA expression levels and poor patient survival for microsomal PGE synthase 1 (mPGES1) and prostaglandin reductase 1 (PTGR1). Conversely, high mRNA expression levels for 15-hydroxyprostaglandin dehydrogenase (15-HPGD) were correlated with better patient survival. GBMs had a higher quantity of the prostanoid precursor, arachidonic acid, versus grade II/III tumors and in GBMs a significant positive correlation was found between arachidonic acid and $\mathrm{PGE}_{2}$ content. GBMs also had higher concentrations of $\mathrm{TXB}_{2}, \mathrm{PGD}_{2}, \mathrm{PGE}_{2}$ and $\mathrm{PGF}_{2 \alpha}$ versus grade II/III tumors. A significant decrease in survival was detected for high versus low $\mathrm{PGE}_{2}, \mathrm{PGE}_{2}$ $+\mathrm{PGE}_{2}$ deactivation products (PGEMs) and $\mathrm{PGF}_{2 \alpha}$ in GBM patients. Our data show the potential importance of prostanoid metabolism in the progression towards GBM and provide evidence that higher $\mathrm{PGE}_{2}$ and $\mathrm{PGF}_{2 \alpha}$ concentrations in the tumor are correlated with poorer patient survival. Our findings highlight the potential importance of the enzymes 15-HPGD and PTGR1 as prognostic biomarkers which could be used to predict survival outcome of patients with GBM. 
Key Words Glioma; prostanoids; prostaglandin $\mathrm{E}_{2}$; 15-hydroxyprostaglandin dehydrogenase; prostaglandin reductase 1

\section{Abbreviations}

Glioblastoma (GBM); polyunsaturated fatty acids (PUFAs); arachidonic acid (AA); prostaglandin (PG); cyclooxygenase 1 or 2 (COX1 or COX2); microsomal PGE synthase 1 or 2 (mPGES1 or mPGES2); cytosolic PGE synthase (cPGES); prostaglandin transport protein (PGT), 15-hydroxyprostaglandin dehydrogenase (15-HPGD); prostaglandin reductase 1 (PTGR1); prostaglandin reductase 2 or 3 (PTGR2 or PTGR3); non-steroidal antiinflammatory drugs (NSAIDs); G protein-coupled receptors for $\mathrm{PGE}_{2} 2$ or 4 (EP2 or EP4); $\mathrm{PGE}_{2}$ deactivation products $\left(\mathrm{PGEMs}=15\right.$-keto $\mathrm{PGE}_{2}$ and 13,14 dihydro, 15-keto $\left.\mathrm{PGE}_{2}\right)$. 


\section{Introduction}

Gliomas are primary tumors of the central nervous system and are considered to be derived from glial cells. The diffuse gliomas are divided into categories including the grade II and III oligodendrogliomas, the grade II and III astrocytomas and the grade IV glioblastoma (GBM). Despite improvements in treatment options which include surgery, radiotherapy and chemotherapy, the prognosis for patients with the higher grade gliomas remains poor and the search for novel treatment strategies is essential for these tumors [1].

Prostanoids are 20-carbon bioactive lipids derived from the metabolism of polyunsaturated fatty acids (PUFAs). Their synthesis is initiated by the hydrolysis of membrane glycerophospholipids through the catalytic activity of cytosolic phospholipase $\mathrm{A}_{2}$ to release 20-carbon PUFAs, the most predominant being arachidonic acid (AA). Prostaglandin endoperoxide $\mathrm{H}$ synthase 1 or 2 , more commonly known as cyclooxygenase $(\mathrm{COX}) 1$ or 2 , then catalyzes a reaction in which molecular oxygen is inserted into AA. The unstable prostaglandin $(\mathrm{PG})$ intermediate which is produced, prostaglandin $\mathrm{G}_{2}\left(\mathrm{PGG}_{2}\right)$, is converted to prostaglandin $\mathrm{H}_{2}\left(\mathrm{PGH}_{2}\right)$ by the peroxidase activity of the COXs [2]. Specific synthases then convert $\mathrm{PGH}_{2}$ into the respective prostaglandins $\left(\mathrm{PGD}_{2}, \mathrm{PGE}_{2}\right.$ and $\left.\mathrm{PGF}_{2 \alpha}\right)$, prostacyclin $\left(\mathrm{PGI}_{2}\right)$ and thromboxane $\left(\mathrm{TXA}_{2}\right)$. The synthesis of $\mathrm{PGE}_{2}$ involves one of three potential enzymes, cytosolic PGE synthase (cPGES), microsomal PGE synthase 1 (mPGES1) and microsomal PGE synthase 2 (mPGES2) [3]. Both COX2 and mPGES1 are inducible enzymes typically upregulated in inflammatory situations and both are known to be overexpressed in several types of cancer [4-7]. In addition, their overexpression is concomitant with the increase in $\mathrm{PGE}_{2}$ content found in many tumors [7-9]. $\mathrm{PGE}_{2}$ is considered to be a major contributor to tumor development and progression through its stimulation of cell proliferation, survival, migration and invasion $[7,10]$. 
While overexpression of PG synthesizing enzymes can obviously contribute to increased PG content in tumors the role of PG deactivation pathways is less well established, particularly in gliomas [10]. The prostaglandin transport protein (PGT), also known as SLCO2A1, is responsible for uptake of PGs from the extracellular space and is thought to be the rate-limiting step for PG deactivation [11]. The first enzyme in the deactivation of $\mathrm{PGE}_{2}$, $\mathrm{PGE}_{1}, \mathrm{PGF}_{2 \alpha}, \mathrm{PGF}_{1 \alpha}$ and $\mathrm{PGI}_{2}$ is $\mathrm{NAD}^{+}$-dependent 15-hydroxyprostaglandin dehydrogenase (15-HPGD) which forms 15-keto PGs, which have significantly reduced biological activity. These 15-keto PGs are then converted to 13, 14-dihydro-15-keto PGs by the prostaglandin reductases (PTGRs) [12]. The PTGR1 enzyme is not only capable of 15-keto PG reduction but also the reduction of leukotriene $\mathrm{B}_{4}$ and lipoxin $\mathrm{A}_{4}$ [13]. Reduced expression of 15HPGD has been reported in some tumors and it has been proposed as a possible tumor suppressor gene in certain tissues including breast, lung, colon, pancreas and bladder [4, 1417]. A recent study also found an association between a single nucleotide polymorphism in the 15-HPGD gene and prostate cancer risk [18]. Whether 15-HPGD acts as a tumor suppressor in gliomas has not been addressed. However, there is evidence in the literature that inhibition of glioma proliferation by non-steroidal anti-inflammatory drugs (NSAIDs) could be mediated partly through upregulation of 15-HPGD [19]. The role of PTGRs in tumor suppression remains inconclusive and is possibly tissue-dependent [20-24]. The prostanoids derived from the activity of $\mathrm{COX}$ and their respective synthases are known to contribute to both active inflammation and immune response in the tumor microenvironment $[7,25]$. Their role in GBM has not yet been fully explored and both their synthesis and deactivation require further study in the search for novel targets for translational research and drug development [10, 26-28].

In the present study we initially determined the expression of the enzymes involved in the synthesis and deactivation of PGs then analyzed the fatty acid composition and PG 
content of grade II, III and IV gliomas. These data were compared with patient survival and significant correlations were identified with $\mathrm{PGE}_{2}$ and $\mathrm{PGF}_{2 \alpha}$ concentrations as well as 15HPGD and PTGR1 mRNA expression levels in tumors. Our findings highlight the potential importance of the enzymes 15-HPGD and PTGR1 as prognostic biomarkers which could be used to predict survival outcome of GBM patients. Controlling the balance between the activities of these two enzymes could also be a promising target for the development of novel treatment options in the future.

\section{Materials and Methods}

Quantitative real time PCR

RNA was isolated from tumor samples frozen and stored in liquid nitrogen, using Trizol reagent (Invitrogen, USA). Complementary DNA (cDNA) synthesis was performed with $1 \mu \mathrm{g}$ total RNA using the MMLV Reverse Transcriptase (Invitrogen) according to the manufacturer's protocol. Real-time PCR was performed using the using the SYBR Green PCR Master Mix with the 7300 Real-Time PCR System (Applied Biosystems). The primers used in this study were as follows (Forward; Reverse):

COX1: GAAACCCTACACCTCCTTCC; CCACTGGCATCGTGATGGA

COX2: TCAGCCATACAGCAAATCCT; CTTGAAGTCGGTAAGTATGTAGTG

mPGES1: CTTGAAGTCGGTAAGTATGTAGTG; CACATCTCAGGTCACGGGTC

mPGES2: CTGTCCCATGGCTACATCCT; CGCCACAAACCTTTCCTTTA

EP2: ACCTACTTCGCTTTCGCCAT; CGTACTGCCCATAGTCCAGC

EP4: GACCTGTTGGGCACTTTGTT; TGGACGCATAGACTGCAAAG

PGT: CCACAGCAGATGAAGCAAGG; GTTCACAGCACCAATGAGG 
15-HPGD: CTTTAGCAGGACTCATGCCC; CAATTGATTCAAGGATGGCTGTG

PGTR1: AATACCACTGTCTTTGGCTCTG; CACTGTTTCTCCACCCTTCAC

18S: CGGCGACGACCCATTCGAAC; GAATCGAACCCTGATTCCCCGTC

HPRT1: TGAGGATTTGGAAAGGGTGT; GAGCACACAGAGGGCTACAA

TBP: CCACTCCACTGTATCCCTCC; GACTGTTCTTCACTCTTGGCT

18S, HPRT1 and TBP were used as housekeeping genes to normalize mRNA expression [29,30]. Data are presented normalized with the expression levels of TBP which had the smallest variation in expression across the patient group (Suppl. Fig. 1). The Ct value of detected genes was obtained from three independent experiments and quantified using the $2-\Delta \Delta \mathrm{Ct}$ method.

Gas Chromatography-Electron Impact Mass Spectrometry

Lipids were extracted from tumor samples frozen and stored in liquid nitrogen by the method of Folch [31] and fatty acid methyl esters were formed by the sulfuric acid/anhydrous methanol method [32]. The fatty acid methyl esters were separated on a DB-23 column [(50\% cyanopropyl)methyl polysiloxane, $0.25 \mu \mathrm{m}$ film thickness, $0.250 \mathrm{~mm}$ x $60 \mathrm{~m}$ ], injection port $220^{\circ} \mathrm{C}$, column-mass spectrometer interface $250^{\circ} \mathrm{C}$, carrier gas helium (99.999\%), in a Shimadzu GCMS model QP5050. The oven program used was as follows: $150^{\circ} \mathrm{C}$ held for $2 \mathrm{~min}$ post injection, then $150-200^{\circ} \mathrm{C}$ at a rate of $10^{\circ} \mathrm{C} / \mathrm{min} ; 200-230^{\circ} \mathrm{C}$ at $1.3^{\circ} \mathrm{C} / \mathrm{min} ; 230-250^{\circ} \mathrm{C}$ at $10^{\circ} \mathrm{C} / \mathrm{min}$. Samples were run in duplicate and individual fatty acid methyl esters were identified by comparison with authentic fatty acid standard retention times and mass spectra [33]. 
Liquid Chromatography-Tandem Mass Spectrometry (LC-MS/MS)

Tumor samples frozen and stored in liquid nitrogen were adjusted to $15 \%(\mathrm{v} / \mathrm{v})$ with ice cold methanol and kept at $4{ }^{\circ} \mathrm{C}$. Freshly prepared internal standard ( $\mathrm{PGB}_{2}$-d4) (40ng) was added to each sample. The samples were centrifuged to remove precipitated proteins and the supernatant was acidified to $\mathrm{pH} 3.0$ with $0.1 \mathrm{M}$ hydrochloric acid then immediately loaded onto C18 SPE cartridges preconditioned with $20 \mathrm{~mL}$ of $15 \%$ methanol and $20 \mathrm{~mL}$ water. After samples were loaded and passed through the SPE column, the cartridges were washed with $20 \mathrm{~mL}$ of $15 \%$ methanol, followed by $20 \mathrm{~mL}$ water, and then $10 \mathrm{~mL}$ of hexane to remove excess water. Finally, eicosanoids were eluted in $15 \mathrm{~mL}$ of methyl formate. The solvent was evaporated under nitrogen in the dark and the residue was dissolved in $100 \mu \mathrm{L}$ of $70 \%$ (v/v) ethanol to be injected into the LC-MS/MS [34].

The Thermo Accela TSQ Quantum Max LC-MS/MS apparatus was operated in the electrospray negative ionization mode. Calibration curves were run for 21 prostanoids containing from $1 \mathrm{pg} / \mu \mathrm{L}$ to $200 \mathrm{pg} / \mu \mathrm{L}$. Optimal conditions for each individual prostanoid were determined by direct infusion of a standard solution of $10 \mathrm{ng} / \mu \mathrm{L}$. Typical parameters for use were: spray voltage $3500 \mathrm{~V}$; discharge current $80 \mathrm{~V}$; capillary temperature $350{ }^{\circ} \mathrm{C}$; collision energy 13-30 V; tube lens 60-93 V; scan time 0.05-0.1 s [35].

A C18 Luna $2.0 \times 150 \mathrm{~mm}, 5 \mu \mathrm{m}$ chromatography column from Phenomenex was used, and the sample volume was $5 \mu \mathrm{L}$ at a flow rate of $350 \mu \mathrm{L} / \mathrm{min}$ with samples kept at $8{ }^{\circ} \mathrm{C}$. Samples were run using Solvent $\mathrm{A}-\mathrm{H}_{2} \mathrm{O}$ (0.2\% acetic acid); solvent $\mathrm{C}$ - acetonitrile $(0.2 \%$ acetic acid). With a gradient as follows: $0-10 \mathrm{~min}, 60 \% \mathrm{~A}: 40 \% \mathrm{C} ; 10.01-13 \mathrm{~min}, 60 \%-10 \%$ A : $40 \%-90 \%$ C; $13.01-15 \min , 10 \%$ A : $90 \%$ C; $15-15.01 \mathrm{~min}, 10 \%-60 \%$ A : $90 \%-40 \%$ C; 15.01-19 min, $60 \%$ A : 40\% C; 19.01 min-end, 100\% A. Samples were run in triplicate and two separate extractions were done for each patient sample. The results were analyzed using 
Thermo XCalibur software and prostanoid concentration was normalized against protein content as ng/mg protein [33].

Patients and glioma samples

Twenty three patients with gliomas were included in the study. The samples included two Grade II astrocytomas, one Grade II oligoastrocytoma, one Grade II oligodendroglioma, three Grade III oligodendrogliomas, and 16 Grade IV GBMs. This study was approved by the Medical Ethics Commission of the Biomedical Institute of the University of Sao Paulo (947/CEP) and by the Medical Ethics Commission of the Santa Casa Hospital in Sao Paulo (162/10). Written informed consent was obtained from all patients.

TCGA and other dataset analysis with GlioVis

The analysis of TCGA, Rembrandt and other datasets was performed using the GlioVis data portal for visualization and analysis of brain tumor expression datasets [36].

Statistical analysis

Where appropriate, data are presented as the mean \pm SEM. Statistical analysis was carried out using GraphPad Prism 5 software and differences were considered to be significant at $\mathrm{p}<0.05$. Statistical tests used on relevant data were one-way ANOVA with Tukey's post-test, Kruskall-Wallis with Dunn's post-test, two-way ANOVA with Bonferroni's post-test, Spearman correlation, Mann-Whitney test and log-rank Mantel-Cox test. The specific test used for each group of data is detailed in the individual figure legends. Data for Kaplan-Meier survival curves were divided into high and low groups based on the median value of all patients for each individual parameter studied (Figs 1, 2, 3, 6 and Suppl. Fig. 2), where high groups were above the median value and low groups were below the 
median value. The median values and curves in Figs 1 and 6 were calculated using GraphPad Prism 5 software while the median values and curves in Figs 2, 3 and Suppl. Fig. 2 were calculated using the GlioVis data portal for visualization and analysis of brain tumor expression datasets [36].

\section{Results}

mRNA expression of prostanoid deactivation pathway enzymes correlates with poor survival

Quantitative real time PCR was used to determine the expression levels of selected proteins of the prostanoid pathway and its G protein-coupled receptors in GBM (Fig. 1A). The expression levels of the prostaglandin $\mathrm{H}$ synthase enzymes commonly referred to as cyclooxygenases 1 and 2 (COX1 and COX2) did not differ significantly from each other (Fig. 1A) and were not correlated with survival (Fig. 1B-C). The prostaglandin E synthase mPGES1 was significantly correlated $(\mathrm{p}=0.0414)$ with patient survival where higher levels of mRNA were correlated with poor survival (Fig. 1D). Median survival for high mPGES1 was 4 months versus 11 months for low mPGES1. The prostaglandin E synthase mPGES2 showed no relation to survival (Fig. 1E). Neither the EP2 nor the EP4 G protein-coupled receptors for $\mathrm{PGE}_{2}$ were found to correlate with survival (Fig. 1F-G). The prostaglandin transport protein PGT, also known as SLCO2A1, responsible for uptake of PG's from the extracellular space also showed no relation to survival (Fig. 1H).

However, when two of the major PG deactivation pathway enzymes were analyzed a significant correlation was found. In the case of the first enzyme in the pathway, 15-HPGD, a significant correlation $(\mathrm{p}=0.0016)$ was found where higher levels of mRNA were correlated with better survival (Fig. 1I) Median survival for high 15-HPGD was 13 months versus 4 
months for low 15-HPGD. On the other hand, the next enzyme in the deactivation pathway, prostaglandin reductase 1 (PTGR1), showed an inverse correlation with survival where lower levels of PTGR1 were correlated with better survival ( $\mathrm{p}=0.0157)$ (Fig. 1J). Median survival for high PGTR1 was 4 months versus 14 months for low PGTR1. Using the mRNA expression ratio of PTGR1/15-HPGD also gave a significant correlation with survival where a high PTGR1/15-HPGD ratio correlated with poor survival (Fig. 1K). Median survival for high PGTR1/15-HPGD was 4 months versus 11 months for low PGTR1/15-HPGD.

In order to validate the results from our patient group, we used GlioVis software to analyze larger GBM datasets including TCGA, Rembrandt and other selected studies. Similar to our results, neither $\mathrm{COX} 1$ nor $\mathrm{COX} 2$ showed convincing correlation with patient survival in most studies despite a significant result for COX1 $(\mathrm{p}=0.0348)$ in the TCGA dataset (Fig. 2A-D). The results for mPGES1 were variable with the RNA seq TCGA data and the Gravendeel study data identifying a significant correlation similar to our data $(\mathrm{p}=0.0327$ and $\mathrm{p}=0.0021$, respectively), while the Rembrandt dataset did not identify a correlation (Fig. 2EG). The mPGES2 enzyme (Fig. 2H) showed no correlation with survival, confirming the results found in our study. The $\mathrm{PGE}_{2} \mathrm{G}$ coupled-receptors EP2 and EP4 (Fig. 3A-B) showed no correlation with survival, also confirming the results found in our study. The PG transporter PGT (SLCO2A1) was also unrelated to survival in the TCGA database as was the case in our study (Fig. 3C).

The 15-HPGD expression levels in the TCGA datasets confirmed our data, showing a significant correlation with survival $(\mathrm{p}=0.0048$ and $\mathrm{p}<0.0001)$ (Fig. 3D-E). The inverse correlation which we identified for PTGR1 in our study was also confirmed in the Rembrandt and Gravendeel datasets ( $\mathrm{p}=0.0056$ and $\mathrm{p}=0.0133$, respectively), where higher PTGR1 was correlated with poor survival (Fig. 3F-G). The PTGR1 gene was not available in the TCGA 
dataset for GBM, but showed a similar inverse correlation with survival in the TCGA low grade glioma dataset $(\mathrm{p}<0.0001)$ (Fig. 3H). Neither PTGR2 nor PTGR3 (ZADH2) expression showed a correlation with patient survival (Suppl. Fig. 2).

Fatty acid composition differs between grade II/III gliomas and GBMs

While the mRNA data showed correlations between certain prostanoid pathway enzymes and patient survival the actual quantity of both fatty acid substrate and prostanoid products needed to be determined in order to make a stronger case for the importance of prostanoid metabolism in GBMs. Gas chromatography-electron impact mass spectrometry was used to determine the fatty acid composition of grade II, grade III and grade IV gliomas in order to identify whether different patterns of fatty acid composition could be detected. The major differences found in grade II/III versus grade IV gliomas was a significant decrease in palmitic acid (16:0), a significant increase in stearic acid (18:0), a significant decrease in oleic acid (18:1) and a significant increase in AA (20:4, n-6) in the grade IV tumors (Fig. 4A). The fatty acid precursor content for AA (20:4, n-6) or dihomo-gammalinolenic acid (20:3, n-6) was plotted against their prostanoid products $\mathrm{PGE}_{2}, \mathrm{PGF}_{2 \alpha}, \mathrm{TXB}_{2}$ and $\mathrm{PGE}_{1}$ (Fig. 4B-E) in the grade IV GBM tumors. Interestingly, a significant correlation between the concentration of precursor versus product was only found for AA and $\mathrm{PGE}_{2}$ (Fig. 4B).

Prostanoid concentration increases from grade II/III gliomas to GBMs

The correlation identified between arachidonic acid and its prostanoid pathway product $\mathrm{PGE}_{2}$ in patient tumors led us to study the profile of prostanoids present in different 
grades of glioma in order to test whether these change as tumor grade progresses. Tumor prostanoid content was determined using liquid chromatography/ electrospray ionization tandem mass spectrometry. Prostanoids of series-1, 2 and 3 were analyzed and comparisons were made between grade II/III and grade IV gliomas. Prostanoids of series-3 were not identified in the samples, reflecting the absence of their precursor fatty acid eicosapentaenoic acid (20:5, n-3) in the tumors (Fig. 4A).

In contrast, prostanoids of series- 1 and -2 were identified in varying concentrations within the patient tumors (Fig. 5A-P). The most abundant prostanoids were $\mathrm{PGE}_{2}, \mathrm{PGF}_{2 \alpha}$ and $\mathrm{PGD}_{2}$, as well as thromboxane $\mathrm{B}_{2}$ which is the deactivation product of the rapidly hydrolyzed thromboxane $\mathrm{A}_{2}$. The series-1 prostanoids were present in lower concentrations than the series-2 prostanoids. Significantly higher concentrations of $\mathrm{TXB}_{2}$ were found in GBMs versus grade II/III tumors, $\mathrm{p}=0.0158$ (Fig. 5B). This was also seen for $\mathrm{PGD}_{2}, \mathrm{p}=0.0043$ (Fig. 5C), $\mathrm{PGF}_{2 \alpha}, \mathrm{p}=0.0027$ (Fig. 5G) and $\mathrm{PGE}_{2}, \mathrm{p}=0.0015$ (Fig. 5I). These data show an increase in prostanoid metabolism of the series-2 as gliomas progress from grade II/III to grade IV.

Prostaglandin $\mathrm{E}_{2}$ and prostaglandin $\mathrm{F}_{2 \alpha}$ concentrations correlate with grade IV GBM patient survival

When the concentration of the significantly altered prostanoids $\mathrm{TXB}_{2}, \mathrm{PGE}_{2}, \mathrm{PGF}_{2 \alpha}$ and $\mathrm{PGD}_{2}$ were plotted against patient survival a significant correlation was found for $\mathrm{PGE}_{2}$. The higher the concentration of $\mathrm{PGE}_{2}$ the poorer was patient survival (Fig. 6A). Median survival for high $\mathrm{PGE}_{2}$ was 3.5 months versus 11 months for low $\mathrm{PGE}_{2}(\mathrm{p}=0.0221)$. When the concentration of the more abundant PGEM 13, 14 dihydro, 15-keto PGE $_{2}$, was plotted against survival no significant correlation was found in GBM patients (Fig. 6B). This was also the case for PGEMs where no significant correlation was found (Fig. 6D). However, when $\mathrm{PGE}_{2}+$ PGEMs (15-keto $\mathrm{PGE}_{2}$ and 13, 14 dihydro, 15-keto $\mathrm{PGE}_{2}$ ) were plotted against 
survival, the higher the concentration of $\mathrm{PGE}_{2}+$ PGEMs the poorer was patient survival (Fig. 6C). Median survival for high $\mathrm{PGE}_{2}+$ PGEMs was 3 months versus 10 months for low $\mathrm{PGE}_{2}$ + PGEMs $(\mathrm{p}=0.0074)$. This was also seen for $\mathrm{PGF}_{2 \alpha}$ where the higher the concentration of $\mathrm{PGF}_{2 \alpha}$ the poorer was patient survival (Fig. 6E). Median survival for high $\mathrm{PGF}_{2 \alpha}$ was 4 months versus 12 months for low $\mathrm{PGF}_{2 \alpha}(\mathrm{p}=0.0112)$. When the concentration of $\mathrm{TXB}_{2}$ or $\mathrm{PGD}_{2}$ was plotted against survival no significant correlation was found in GBM patients (Fig. 6F-G).

\section{Discussion}

In this study, we investigated the relationship between the expression of enzymes and products of the prostanoid pathway and patient survival in GBM. While a possible role of the mPGES1 enzyme in patient survival was found in our study and in other datasets, not all studies have identified this enzyme as a predictor of survival in GBM. However, future functional studies should be directed towards identifying the importance of mPGES1 as a potential therapeutic target in GBM as it is already considered a possible target in several cancers [37, 38] with inhibitors available for clinical testing and trials including GRC27864 and LY3023703 [9, 39, 40].

Novel findings in this study were the correlations found between enzymes of the prostanoid deactivation pathway and GBM patient survival. While the synthesis of prostanoids is increased in GBMs little is known about the deactivation pathway in these tumors. The first enzyme in the pathway 15-HPGD was correlated with patient survival, with higher mRNA levels of 15-HPGD found in patients with better survival outcomes. This is compatible with the idea that potentially increased inactivation of prostanoids such as $\mathrm{PGE}_{2}$ through enzymatic deactivation could be important for survival. Survival curves from larger 
datasets also showed a significant relationship between higher 15-HPGD levels and longer survival.

The microRNA miR-21 is a $\mathrm{PGE}_{2}$-induced negative regulator of 15-HPGD expression in cholangiocarcinoma and tongue squamous cell carcinoma [41, 42]. miR-21 is also reported to modulate PG signaling and gastric tumorigenesis at least in part through 15-HPGD [43]. This is particularly interesting when we consider glioma studies where miR-21 is upregulated as glioma grade increases, becoming almost twenty-fold higher in GBM samples [44]. It will be an important area of future research to determine whether the increased miR-21 reported in GBM is functionally related to reduced $15-\mathrm{HPGD}$, increased $\mathrm{PGE}_{2}$ concentrations and poor patient survival. Another important point is that the deactivation product produced by 15-HPGD's action on $\mathrm{PGE}_{2}, 15$-keto $\mathrm{PGE}_{2}$, is now recognized to be a potent PPAR $\gamma$ ligand [45, 46]. 15-keto $\mathrm{PGE}_{2}$ opposes the stimulatory effects of $\mathrm{PGE}_{2}$ on tumor growth by activating PPAR $\gamma$ which leads to an increase the expression of the cyclin-dependent kinase inhibitor p21 and the blockade of the cell cycle in hepatocellular carcinoma [47]. This is another avenue of research which is worthy of investigation as the balance between $\mathrm{PGE}_{2}$ and 15-keto $\mathrm{PGE}_{2}$ could be therapeutically altered with compounds known to increase 15-HPGD expression $[48,49]$.

In direct contrast to the findings with 15-HPGD, the second enzyme in the prostanoid deactivation pathway PTGR1 was found to be inversely correlated with patient survival. In this case higher mRNA levels of PTGR1 were found in patients with poor survival outcomes. Survival curves from larger datasets also showed a significant relationship between higher PTGR1 levels and shorter survival. Although this may at first appear counterintuitive it seems that higher PTGR1 activity could be advantageous to the tumor. Considering that 15 -keto $\mathrm{PGE}_{2}$ may inhibit proliferation as mentioned above for hepatocellular carcinoma, a high level 
of PTGR1 expression would allow the rapid deactivation of this PPAR $\gamma$ ligand. In our patient data $\mathrm{PGE}_{2}$ content was higher in GBM than in grade II/III tumors and 15-keto $\mathrm{PGE}_{2}$ was almost equal, but the PTGR1 product 13, 14 dihydro, 15-keto $\mathrm{PGE}_{2}$ had a tendency to be higher in GBM, suggesting that potentially inhibitory 15 -keto $\mathrm{PGE}_{2}$ is degraded efficiently by the high PTGR1 levels. In support of this, the PGEM 13, 14 dihydro, 15-keto $\mathrm{PGE}_{2}$ is more abundant than 15-keto $\mathrm{PGE}_{2}$ in the GBM samples. The fact that higher PTGR1 expression was in turn correlated with poorer survival suggests that the deactivation of $15-$ keto $\mathrm{PGE}_{2}$ may be important and should be investigated further to determine whether this could be a target for drug development in GBM as well as other cancers [50].

The differences in fatty acid composition seen between grade II/III and grade IV tumors were particularly marked for AA. An earlier study showed that AA content increased in glioma versus normal brain [51]. In GBM, the AA content was significantly correlated to the concentration of $\mathrm{PGE}_{2}$ but not $\mathrm{PGF}_{2 \alpha}$ or $\mathrm{TXB}_{2}$, further suggesting the importance of $\mathrm{PGE}_{2}$ concentration in these tumors. The fact that AA correlated with $\mathrm{PGE}_{2}$ in GBM's led us to evaluate the prostanoid profile of gliomas in detail. We found that an increase in series-2 prostanoid concentrations was evident in GBM in comparison with grade II/III tumors. When we compared the prostanoid concentration with GBM patient survival a significant correlation was seen for $\mathrm{PGE}_{2}, \mathrm{PGE}_{2}+\mathrm{PGEMs}$ and $\mathrm{PGF}_{2 \alpha}$. No survival correlation was seen for $\mathrm{TXB}_{2}$ or $\mathrm{PGD}_{2}$ in these patients. The results again point to the importance of $\mathrm{PGE}_{2}$ in GBM and highlight $\mathrm{PGF}_{2 \alpha}$ as another series-2 prostanoid of importance in GBM cell biology. Functional studies to discover the role of $\mathrm{PGF}_{2 \alpha}$ in GBM and to expand the understanding of $\mathrm{PGE}_{2}$ 's role in GBM may point to potentially novel targets for the development of new therapeutic approaches to the control of glioma cell proliferation, cell death and migration. 
To our knowledge, this is the first report linking prostanoid metabolism and in particular the enzymes mediating their deactivation to survival in glioma patients. The intratumoral concentrations of $\mathrm{PGE}_{2}$ and its deactivation products are related to patient survival as is the concentration of $\mathrm{PGF}_{2 \alpha}$. Our findings highlight the potential importance of the enzymes 15-HPGD and PTGR1 as prognostic biomarkers which could be used to predict survival outcome of GBM patients. Controlling the balance between the activities of these two enzymes could also be a promising target for the development of novel treatment options in the future.

\section{Funding}

This study was funded by research grants from the São Paulo State Research Foundation (FAPESP) -10/51999-0, 15/08777-0, as well as grants from CNPq and CAPES. 


\section{References}

1. Louis DN, Perry A, Reifenberger G, von Deimling A, Figarella-Branger D, Cavenee WK,

Ohgaki H, Wiestler OD, Kleihues P, Ellison DW. The 2016 World Health Organization Classification of Tumors of the Central Nervous System: a summary. Acta Neuropathol. 2016; 131(6):803-20.

2. Massey KA, Nicolaou A. Lipidomics of polyunsaturated-fatty-acid-derived oxygenated metabolites. Biochem Soc Trans. 2011; 39(5):1240-6.

3. Hara S, Kamei D, Sasaki Y, Tanemoto A, Nakatani Y, Murakami M. Prostaglandin E synthases: Understanding their pathophysiological roles through mouse genetic models. Biochimie. 2010; 92(6):651-9.

4. Hughes D, Otani T, Yang P, Newman RA, Yantiss RK, Altorki NK, Port JL, Yan M, Markowitz SD, Mazumdar M, Tai HH, Subbaramaiah K, Dannenberg AJ. NAD+-dependent 15-hydroxyprostaglandin dehydrogenase regulates levels of bioactive lipids in non-small cell lung cancer. Cancer Prev Res (Phila). 2008;1(4):241-9.

5. Panagopoulos AT, Lancellotti CL, Veiga JC, de Aguiar PH, Colquhoun A. Expression of cell adhesion proteins and proteins related to angiogenesis and fatty acid metabolism in benign, atypical, and anaplastic meningiomas. J Neurooncol. 2008;89(1):73-87.

6. Mattila S, Tuominen H, Koivukangas J, Stenbäck F. The terminal prostaglandin synthases mPGES-1, mPGES-2, and cPGES are all overexpressed in human gliomas. Neuropathology. 2009;29(2):156-65.

7. Wang D, Dubois RN. Eicosanoids and cancer. Nat Rev Cancer. 2010;10(3):181-93. 
8. Shono T, Tofilon PJ, Bruner JM, Owolabi O, Lang FF. Cyclooxygenase-2 expression in human gliomas: prognostic significance and molecular correlations. Cancer Res. 2001;61(11):4375-81.

9. Koeberle A, Laufer SA, Werz O. Design and Development of Microsomal Prostaglandin E2 Synthase-1 Inhibitors: Challenges and Future Directions. J Med Chem. 2016;59(13):597086.

10. Colquhoun A. Cell biology-metabolic crosstalk in glioma. Int J Biochem Cell Biol. 2017;89:171-81.

11. Nakanishi T, Tamai I. Roles of Organic Anion Transporting Polypeptide 2A1 (OATP2A1/SLCO2A1) in Regulating the Pathophysiological Actions of Prostaglandins. AAPS J. 2017;20(1):13.

12. Tai HH. Prostaglandin catabolic enzymes as tumor suppressors. Cancer Metastasis Rev. 2011;30(3-4):409-17.

13. Hori T, Yokomizo T, Ago H, Sugahara M, Ueno G, Yamamoto M, Kumasaka T, Shimizu T, Miyano M. Structural basis of leukotriene B4 12-hydroxydehydrogenase/15-Oxoprostaglandin 13-reductase catalytic mechanism and a possible Src homology 3 domain binding loop. J Biol Chem. 2004;279(21):22615-23.

14. Pham H, Chen M, Li A, King J, Angst E, Dawson DW, Park J, Reber HA, Hines OJ, Eibl G. Loss of 15-hydroxyprostaglandin dehydrogenase increases prostaglandin E2 in pancreatic tumors. Pancreas. 2010;39(3):332-9.

15. Yang JE, Park E, Lee HJ, Kang HJ, Kim KM, Yu E, Lee D, Shim JH, Lim YS, Lee HC, Chung YH, Lee YS. Role of 15-hydroxyprostaglandin dehydrogenase down-regulation on the prognosis of hepatocellular carcinoma. Clin Mol Hepatol. 2014;20(1):28-37. 
16. Cebola I, Custodio J, Muñoz M, Díez-Villanueva A, Paré L, Prieto P, Aussó S, CollMulet L, Boscá L, Moreno V, Peinado MA. Epigenetics override pro-inflammatory PTGS transcriptomic signature towards selective hyperactivation of PGE2 in colorectal cancer. Clin Epigenetics. 2015;7:74.

17. Yang DH, Ryu YM, Lee SM, Jeong JY, Yoon SM, Ye BD, Byeon JS, Yang SK, Myung SJ. 15-Hydroxyprostaglandin dehydrogenase as a marker in colon carcinogenesis: analysis of the prostaglandin pathway in human colonic tissue. Intest Res. 2017;15(1):75-82.

18. Qi X, Wang Y, Hou J, Huang Y. A Single Nucleotide Polymorphism in 15-HPGD Gene Is Associated with Prostate Cancer Risk. J Cancer. 2017;8(19):4083-86.

19. Wakimoto N, Wolf I, Yin D, O'Kelly J, Akagi T, Abramovitz L, Black KL, Tai HH, Koeffler HP. Nonsteroidal anti-inflammatory drugs suppress glioma via 15hydroxyprostaglandin dehydrogenase. Cancer Res. 2008;68(17):6978-86.

20. Chang EY, Tsai SH, Shun CT, Hee SW, Chang YC, Tsai YC, Tsai JS, Chen HJ, Chou JW, Lin SY, Chuang LM. Prostaglandin reductase 2 modulates ROS-mediated cell death and tumor transformation of gastric cancer cells and is associated with higher mortality in gastric cancer patients. Am J Pathol. 2012;181(4):1316-26.

21. Chang EY, Chang YC, Shun CT, Tien YW, Tsai SH, Hee SW, Chen IJ, Chuang LM. Inhibition of Prostaglandin Reductase 2, a Putative Oncogene Overexpressed in Human Pancreatic Adenocarcinoma, Induces Oxidative Stress-Mediated Cell Death Involving xCT and CTH Gene Expressions through 15-Keto-PGE2. PLoS One. 2016;11(1):e0147390.

22. Xue L, Zhu Z, Wang Z, Li H, Zhang P, Wang Z, Chen Q, Chen H, Chong T. Knockdown of prostaglandin reductase 1 (PTGR1) suppresses prostate cancer cell proliferation by inducing cell cycle arrest and apoptosis. Biosci Trends. 2016;10(2):133-9. 
23. Sánchez-Rodríguez R, Torres-Mena JE, Quintanar-Jurado V, Chagoya-Hazas V, Rojas Del Castillo E, Del Pozo Yauner L, Villa-Treviño S, Pérez-Carreón JI. Ptgr1 expression is regulated by NRF2 in rat hepatocarcinogenesis and promotes cell proliferation and resistance to oxidative stress. Free Radic Biol Med. 2017;102:87-99.

24. Laks DR, Crisman TJ, Shih MY, Mottahedeh J, Gao F, Sperry J, Garrett MC, Yong WH, Cloughesy TF, Liau LM, Lai A, Coppola G, Kornblum HI. Large-scale assessment of the gliomasphere model system. Neuro Oncol. 2016;18(10):1367-78.

25. Nathoo N, Barnett GH, Golubic M. The eicosanoid cascade: possible role in gliomas and meningiomas. J Clin Pathol. 2004;57(1):6-13.

26. De Armas R, Durand K, Guillaudeau A, Weinbreck N, Robert S, Moreau JJ, Caire F, Acosta G, Pebet M, Chaunavel A, Marin B, Labrousse F, Denizot Y. mRNA levels of enzymes and receptors implicated in arachidonic acid metabolism in gliomas. Clin Biochem. 2010;43(10-11):827-35.

27. Cook PJ, Thomas R, Kingsley PJ, Shimizu F, Montrose DC, Marnett LJ, Tabar VS, Dannenberg AJ, Benezra R. Cox-2-derived PGE2 induces Id1-dependent radiation resistance and self-renewal in experimental glioblastoma. Neuro Oncol. 2016;18(10):1379-89.

28. Qiu J, Shi Z, Jiang J. Cyclooxygenase-2 in glioblastoma multiforme. Drug Discov Today. 2017;22(1):148-56.

29. Vandesompele J, De Preter K, Pattyn F, Poppe B, Van Roy N, De Paepe A, Speleman F. Accurate normalization of real-time quantitative RT-PCR data by geometric averaging of multiple internal control genes. Genome Biol. 2002;3(7):Research0034. 
30. Valente V, Teixeira SA, Neder L, Okamoto OK, Oba-Shinjo SM, Marie SK, Scrideli CA, Paçó-Larson ML, Carlotti CG Jr. Selection of suitable housekeeping genes for expression analysis in glioblastoma using quantitative RT-PCR. Ann Neurosci. 2014;21(2):62-3.

31. Folch J, Lees M, Sloane Stanley GH. A simple method for the isolation and purification of total lipids from animal tissues. J Biol Chem. 1957;226(1):497-509.

32. Kitson G, Larsen BS, McEwen CN, eds. Gas chromatography and mass spectrometry: a practical guide. New York: Academic Press. 1996:337.

33. Ramos KL, Colquhoun A. Protective role of glucose-6-phosphate dehydrogenase activity in the metabolic response of C6 rat glioma cells to polyunsaturated fatty acid exposure. Glia. 2003;43(2):149-66.

34. Massey KA, Nicolaou A. Lipidomics of oxidized polyunsaturated fatty acids. Free Radic Biol Med. 2013;59:45-55.

35. Ferreira MT, Gomes RN, Panagopoulos AT, de Almeida FG, Veiga JCE, Colquhoun A. Opposing roles of PGD2 in GBM. Prostaglandins Other Lipid Mediat. 2018, 134; 66-76.

36. Bowman RL, Wang Q, Carro A, Verhaak RG, Squatrito M. GlioVis data portal for visualization and analysis of brain tumor expression datasets. Neuro Oncol. 2017;19(1):13941.

37. Larsson K, Jakobsson PJ. Inhibition of microsomal prostaglandin E synthase-1 as targeted therapy in cancer treatment. Prostaglandins Other Lipid Mediat. 2015;120:161-65.

38. Sasaki Y, Nakatani Y, Hara S. Role of microsomal prostaglandin E synthase-1 (mPGES1)-derived prostaglandin E2 in colon carcinogenesis. Prostaglandins Other Lipid Mediat. 2015;121(Pt A):42-5. 
39. ClinicalTrials.gov Identifier: NCT02361034: To Evaluate Safety, Tolerability and Pharmacokinetics of GRC 27864 in Healthy Subjects and Elderly Healthy Subjects mPGEs1 inhibitor

40. ClinicalTrials.gov Identifier: NCT01849055: A multiple dose study of LY3023703 in healthy participants

41. Lu L, Byrnes K, Han C, Wang Y, Wu T. miR-21 targets 15-HPGD and promotes cholangiocarcinoma growth. Mol Cancer Res. 2014;12(6):890-900.

42. He Q, Chen Z, Dong Q, Zhang L, Chen D, Patel A, Koya A, Luan X, Cabay RJ, Dai Y, Wang A, Zhou X. MicroRNA-21 regulates prostaglandin E2 signaling pathway by targeting 15-hydroxyprostaglandin dehydrogenase in tongue squamous cell carcinoma. BMC Cancer. 2016;16(1):685.

43. Li L, Wang X, Li W, Yang L, Liu R, Zeng R, Wu Y, Shou T. miR-21 modulates prostaglandin signaling and promotes gastric tumorigenesis by targeting 15-HPGD. Biochem Biophys Res Commun. 2018;495(1):928-34.

44. Koshkin PA, Chistiakov DA, Nikitin AG, Konovalov AN, Potapov AA, Usachev DY, Pitskhelauri DI, Kobyakov GL, Shishkina LV, Chekhonin VP. Analysis of expression of microRNAs and genes involved in the control of key signaling mechanisms that support or inhibit development of brain tumors of different grades. Clin Chim Acta. 2014;430:55-62.

45. Snyder NW, Golin-Bisello F, Gao Y, Blair IA, Freeman BA, Wendell SG. 15Oxoeicosatetraenoic acid is a 15-hydroxyprostaglandin dehydrogenase-derived electrophilic mediator of inflammatory signaling pathways. Chem Biol Interact. 2015;234:144-53. 
46. Yao L, Han C, Song K, Zhang J, Lim K, Wu T. Omega-3 Polyunsaturated Fatty Acids Upregulate 15-HPGD Expression in Cholangiocarcinoma Cells by Inhibiting miR-26a/b Expression. Cancer Res. 2015;75(7):1388-98.

47. Lu D, Han C, Wu T. 15-HPGD inhibits hepatocellular carcinoma growth through 15keto-PGE2/PPAR $\gamma$-mediated activation of p21WAF1/Cip1. Oncogene. 2014;33(9):1101-12.

48. Wang W, Hu Y, Wang X, Wang Q, Deng H. ROS-Mediated 15-Hydroxyprostaglandin Dehydrogenase Deactivation via Cysteine Oxidation Promotes NAD(+)-Mediated EpithelialMesenchymal Transition. Cell Chem Biol. 2017 In press.

49. Yao L, Chen W, Song K, Han C, Gandhi CR, Lim K, Wu T. 15 hydroxyprostaglandin dehydrogenase (15-HPGD) prevents lipopolysaccharide (LPS)-induced acute liver injury. PLoS One. 2017;12(4):e0176106.

50. Mesa J, Alsina C, Oppermann U, Parés X, Farrés J, Porté S. Human prostaglandin reductase 1 (PGR1): Substrate specificity, inhibitor analysis and site-directed mutagenesis. Chem Biol Interact. 2015;234:105-13.

51. Kökoğlu E, Tüter Y, Sandikçi KS, Yazici Z, Ulakoğlu EZ, Sönmez H, Ozyurt E. Prostaglandin E2 levels in human brain tumor tissues and arachidonic acid levels in the plasma membrane of human brain tumors. Cancer Lett. 1998;132(1-2):17-21. 


\section{Figure Legends}

Fig. 1. mRNA expression of selected enzymes and receptors involved in prostanoid biology versus patient survival.

mRNA expression of selected proteins in grade IV GBM tumors, $n=11$, mean \pm SEM (A). Kaplan-Meier survival curves for mRNA expression in GBM tumors (B) cyclooxygenase 1 (C) cyclooxygenase 2 (D) microsomal PGE synthase 1 (E) microsomal PGE synthase 2 (F) PGE receptor EP2 (G) PGE receptor EP4 (H) prostaglandin transporter (SLCO2A1) (I) 15hydroxyprostaglandin dehydrogenase $(\mathrm{J})$ prostaglandin reductase $1(\mathrm{~K})$ ratio of prostaglandin reductase 1: 15-hydroxyprostaglandin dehydrogenase. B-H, n=8; I-K, n=11. High and low expression was based on median expression levels for each protein and expression was normalized against the TBP gene which showed the smallest variation among GBM tumors (see Suppl. Fig. 1). The log-rank Mantel-Cox test was used with differences considered significant at $\mathrm{p}<0.05$. mPGES1, 15-HPGD, PTGR1 and PTGR1/15-HPGD expression were significantly correlated with patient survival.

Fig. 2. Prostanoid pathway mRNA expression versus patient survival in selected databases

Kaplan-Meier survival curves for mRNA expression in grade IV GBM tumors from selected databases using Gliovis software for analysis. (A-B) cyclooxygenase 1, TCGA and Rembrandt (C-D) cyclooxygenase 2, TCGA and Rembrandt (E-G) microsomal PGE synthase 1, TCGA (R), Rembrandt and Gravendeel (H) microsomal PGE synthase 2, Rembrandt. High and low expression was based on median expression levels for each protein. The logrank Mantel-Cox test was used with differences considered significant at $\mathrm{p}<0.05$. TCGA data using different datasets:- TCGA - HG-U133A; TCGA (R) - RNASeq. mPGES1 expression was significantly correlated with patient survival. 
Fig. 3. Prostanoid pathway mRNA expression versus patient survival in selected databases

Kaplan-Meier survival curves for mRNA expression in grade IV GBM tumors from selected databases using Gliovis software for analysis. (A) PGE receptor EP2, TCGA (B) PGE receptor EP4, TCGA (C) prostaglandin transporter (SLCO2A1), TCGA (D-E) 15hydroxyprostaglandin dehydrogenase, TCGA and TCGA (A) (F-G) prostaglandin reductase 1, Rembrandt and Gravendeel $(\mathrm{H})$ prostaglandin reductase 1, TCGA, low-grade glioma. High and low expression was based on median expression levels for each protein. The log-rank Mantel-Cox test was used with differences considered significant at $\mathrm{p}<0.05$. TCGA data using different datasets:- TCGA - HG-U133A; TCGA (A) - Agilent-4502A. 15-HPGD and PTGR1 expression were significantly correlated with patient survival.

Fig. 4. Fatty acid composition and prostanoids found in patient tumors

GCMS analysis of tumor fatty acid composition (A) grade II/III patients, $n=7$ and grade IV GBM patients, $n=12$. Correlation of fatty acid substrate with prostanoid product in GBM tumors, n=12 (B) arachidonic acid (20:4, n-6) versus $\mathrm{PGE}_{2}$ (C) dihomo gamma-linolenic acid (20:3, n-6) versus $\mathrm{PGE}_{1}$ (D) arachidonic acid (20:4, n-6) versus $\mathrm{PGF}_{2 \alpha}$ (E) arachidonic acid (20:4, n-6) versus $\mathrm{TXB}_{2}$. Two-way ANOVA with Bonferroni post-test was used for composition versus grade, with differences considered significant at $\mathrm{p}<0.05$. Spearman correlation was used for substrate to product correlation with differences considered significant at $\mathrm{p}<0.05$. The $\%$ of arachidonic acid increased between grade II/III and GBM tumors and in GBM tumors the content of arachidonic acid was significantly correlated with the $\mathrm{PGE}_{2}$ concentration of the tumor. 
Fig. 5. Correlations between prostanoid concentrations and tumor grade

LC-MS/MS analysis of tumor prostanoid concentrations (A) 6-keto $\mathrm{PGF}_{1 \alpha}$ (B) $\mathrm{TXB}_{2}$ (C) $\mathrm{PGD}_{2}$ (D) $\mathrm{PGJ}_{2}$ (E) $\Delta^{12} \mathrm{PGJ}_{2}$ (F) 15 -deoxy- $\Delta^{12,14} \mathrm{PGJ}_{2}$ (G) $\mathrm{PGF}_{2 \alpha}$ (H) 13, 14 dihydro, 15keto $\mathrm{PGF}_{2 \alpha}$ (I) $\mathrm{PGE}_{2}$ (J) 15-keto $\mathrm{PGE}_{2}(\mathrm{~K})$ 13, 14 dihydro, 15-keto $\mathrm{PGE}_{2}$ (L) $\mathrm{PGD}_{1}$ (M) PGE 1 (N) 13, 14 dihydro, 15-keto $\mathrm{PGE}_{1}(\mathrm{O}) \mathrm{PGF}_{1 \alpha}$ (P) 13, 14 dihydro, 15-keto PGF $1 \alpha$. Series-2 PGs presented in A-K and Series-1 PGs presented in L-P. The Mann-Whitney test was used to compare prostanoid concentration with tumor grade and differences were considered significant at $\mathrm{p}<0.05$. Grade II/III, $\mathrm{n}=7$; grade IV, $\mathrm{n}=16$. Significantly higher concentrations of $\mathrm{TXB}_{2}, \mathrm{PGD}_{2}, \mathrm{PGF}_{2 \alpha}$, and $\mathrm{PGE}_{2}$ were found in grade IV versus grade II/III tumors.

Fig. 6. Correlations between prostanoid concentrations and patient survival

Kaplan-Meier survival curves for prostanoid concentration in grade IV GBM tumors, $n=10$

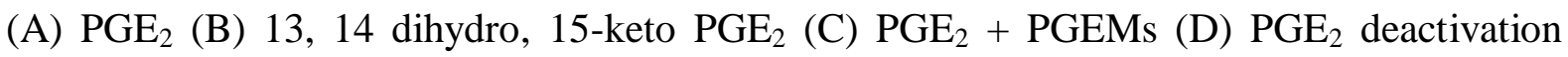
metabolites - 15-keto $\mathrm{PGE}_{2}$ and 13, 14 dihydro, 15-keto $\mathrm{PGE}_{2}(\mathrm{PGEMs})(\mathrm{E}) \mathrm{PGF}_{2 \alpha}(\mathrm{F}) \mathrm{TXB}_{2}$ (G) PGD $_{2}$. High and low concentration was based on median values for each prostanoid. The log-rank Mantel-Cox test was used with differences considered significant at $\mathrm{p}<0.05$. $\mathrm{PGE}_{2}$, $\mathrm{PGE}_{2}+$ PGEM's and $\mathrm{PGF}_{2 \alpha}$ concentrations were significantly correlated with patient survival.

\section{Table}

Table 1. Patient characteristics (all patients, $n=23$ )

Kruskal-Wallis with Dunn's post-test was used to compare age differences among groups, $\mathrm{p}=0.0164$. 


\section{Supplementary Figures}

Supplementary Fig. 1 Variation in housekeeping reference genes among GBM patient samples

Quantitative real time PCR was used to determine the mean $\mathrm{Ct}$ value $\pm \mathrm{SEM}$ for the three housekeeping genes $18 \mathrm{~S}$ ribosomal RNA (18S), TATA box binding protein (TBP) and Hypoxanthine phosphoribosyltransferase 1 (HPRT1). One way ANOVA with Tukey's posttest was used with differences considered significant at $\mathrm{p}<0.05$.

Supplementary Fig. 2 mRNA expression data versus patient survival for prostaglandin reductase 2 and 3

Kaplan-Meier survival curves for mRNA expression in grade IV tumors from selected databases using Gliovis software for analysis. High and low expression was based on median expression levels for each protein. Rembrandt, Gravendeel, TCGA (Agilent 4502A) and TCGA RNASeq databases showed no correlation with patient survival unlike those found for PTGR1 in Fig. 1 and 3. 
Table 1 Patient characteristics (all patients, $n=23$ )

\begin{tabular}{|l|c|c|c|}
\hline & Grade II & Grade III & Grade IV \\
\hline $\mathrm{n}$ & 4 & 3 & 16 \\
\hline Age, $\mathrm{y}$ & $41.00 \pm 5.05$ & $49.33 \underline{ \pm} .18$ & $58.13 \pm 1.98$ \\
\hline Mean \pm SEM & $2(50)$ & $2(66.7)$ & $12(75)$ \\
\hline Gender & $2(50)$ & $1(33.3)$ & $4(25)$ \\
\hline Male $(\%)$ & \multicolumn{5}{|l|}{} \\
\hline Female $(\%)$ &
\end{tabular}

Age difference among groups by Kruskal-Wallis with Dunn's post-test, $\mathrm{p}=0.0164$. 
Fig. 1 mRNA expression of selected enzymes and receptors involved in prostanoid biology versus patient survival

A

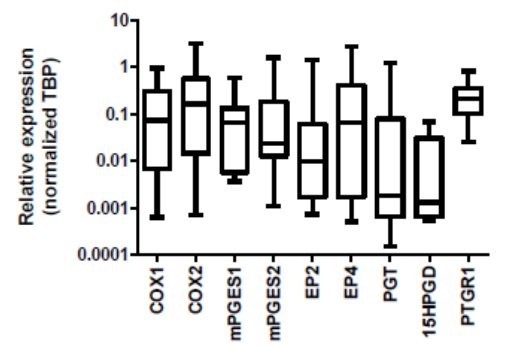

B

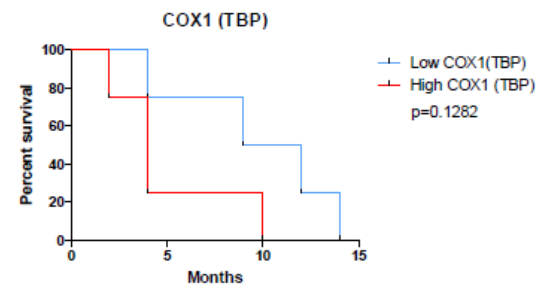

D

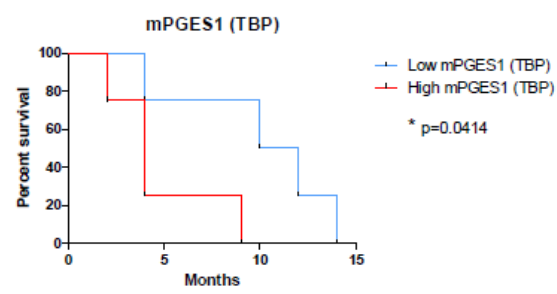

$\mathbf{F}$

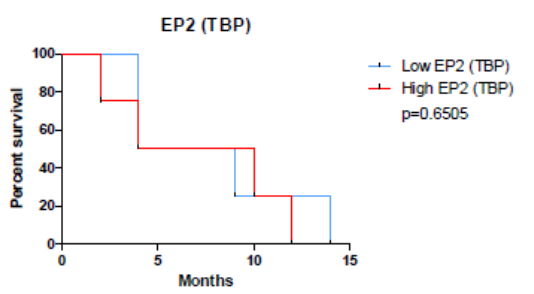

H

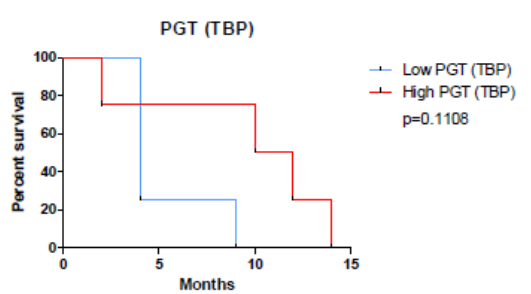

$\mathbf{J}$

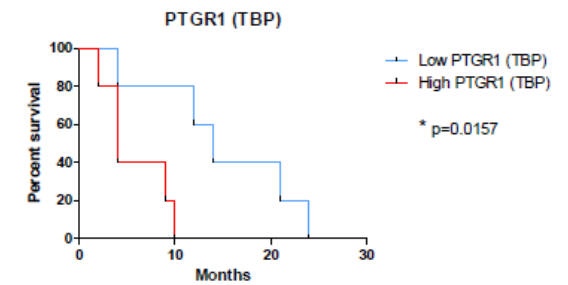

C

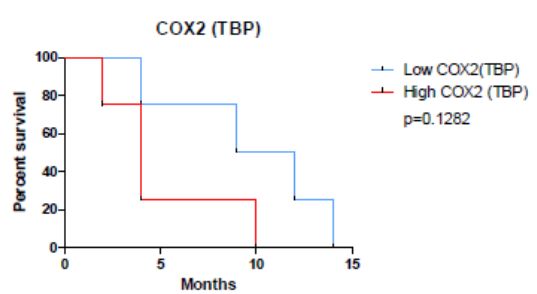

E

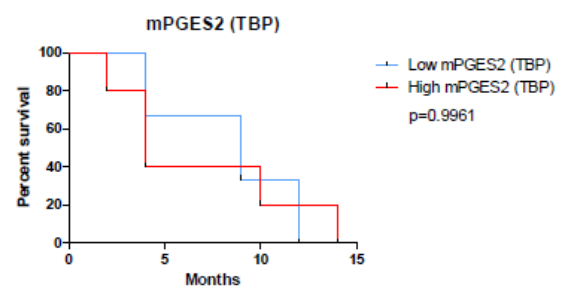

G

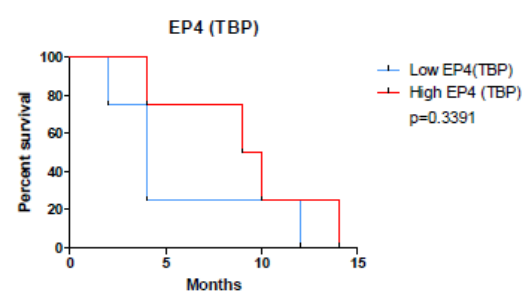

I

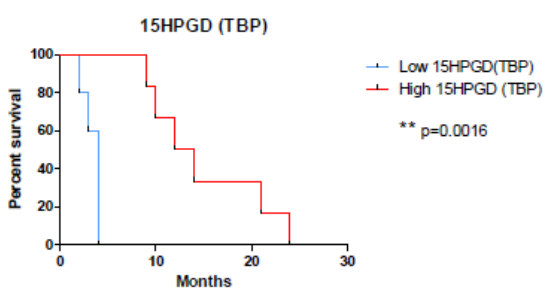

K

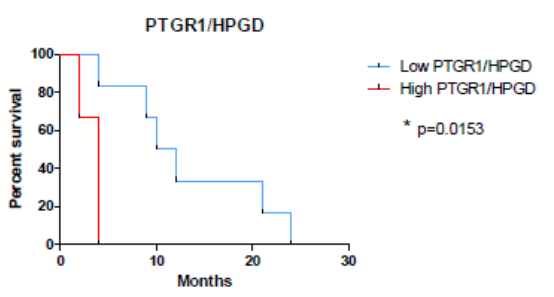


Fig. 2 Prostanoid pathway mRNA expression versus patient survival in selected databases
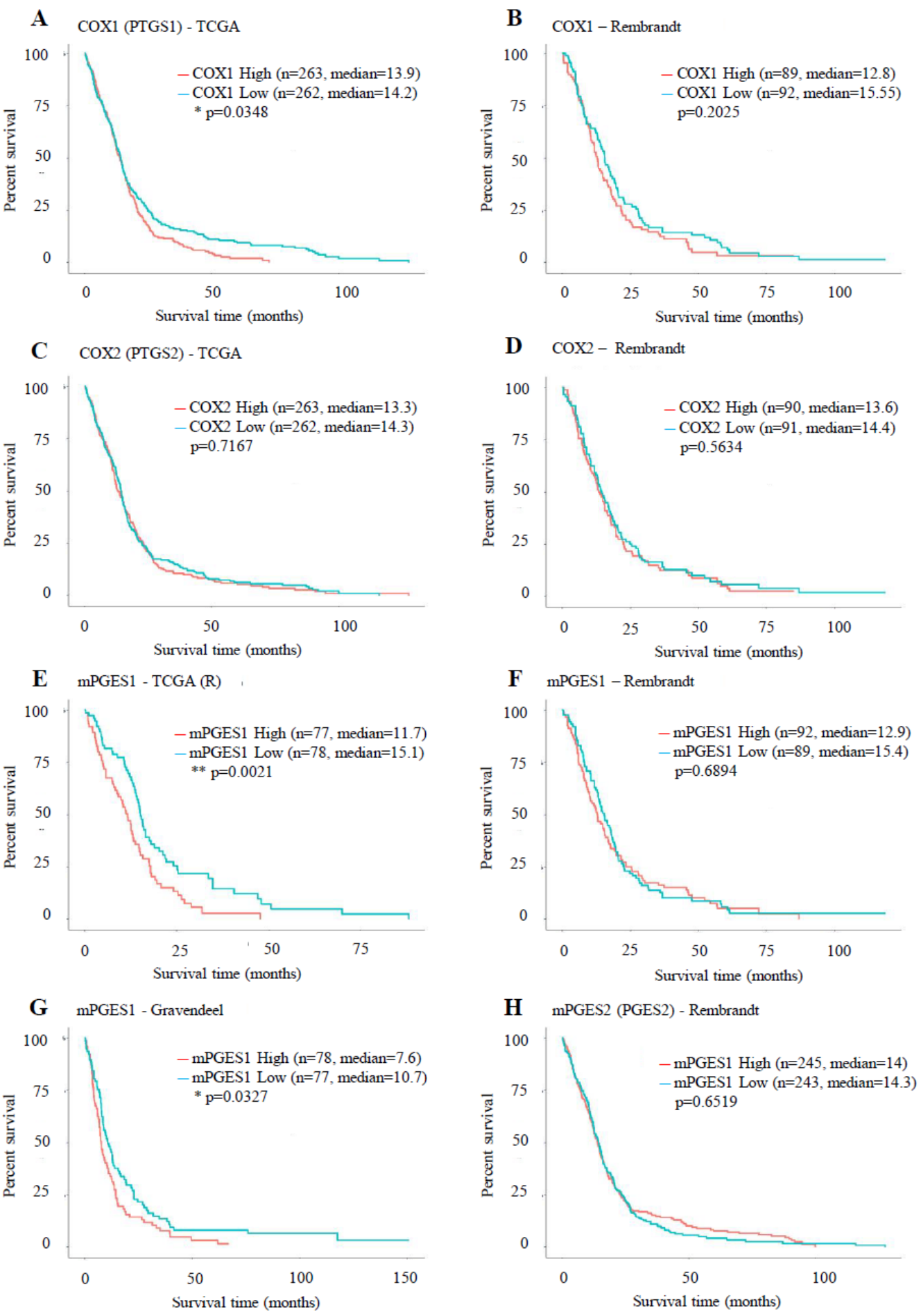
Fig. 3 Prostanoid pathway mRNA expression versus patient survival in selected databases
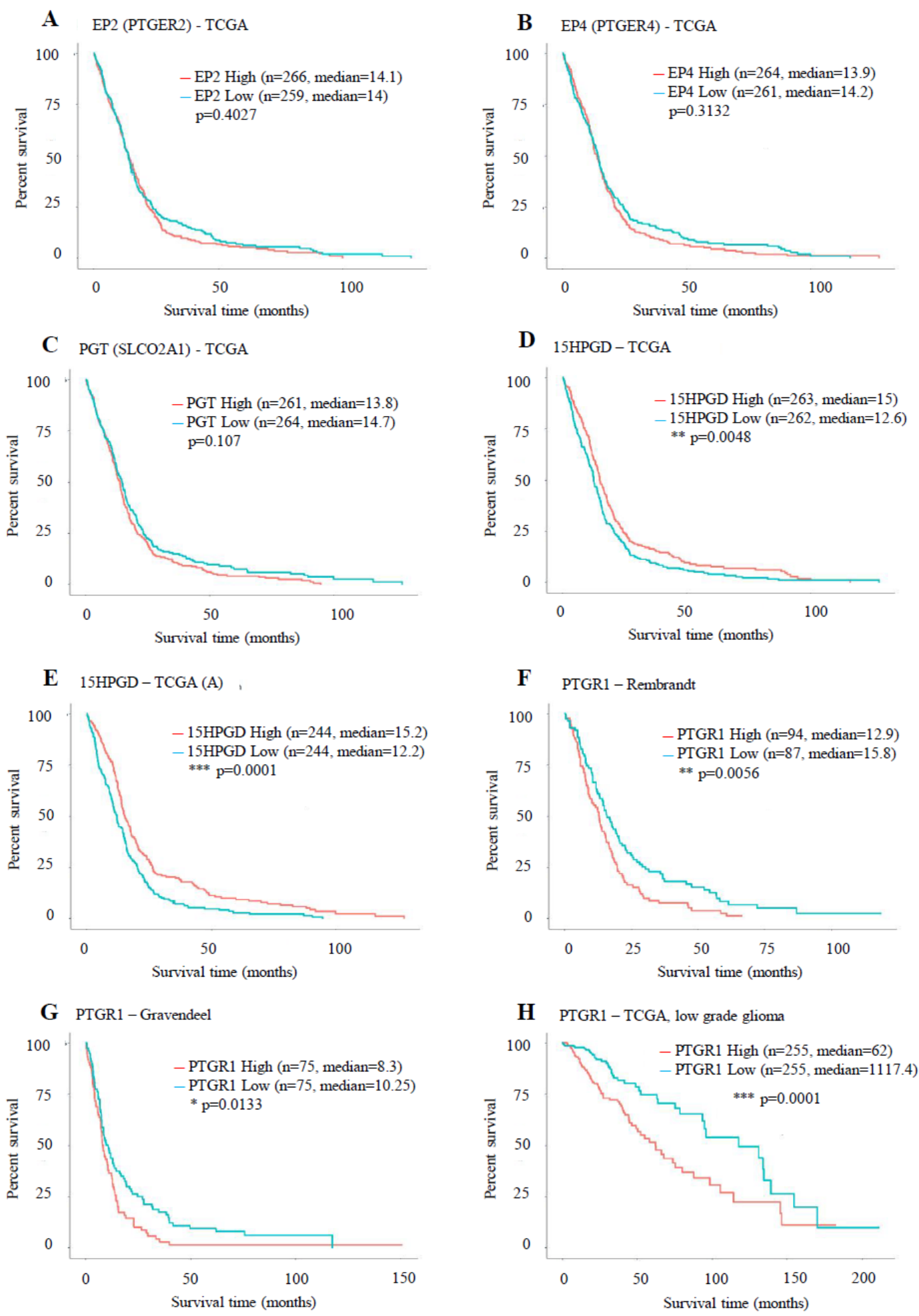
Fig. 4 Fatty acid composition and prostanoids found in patient tumors

A

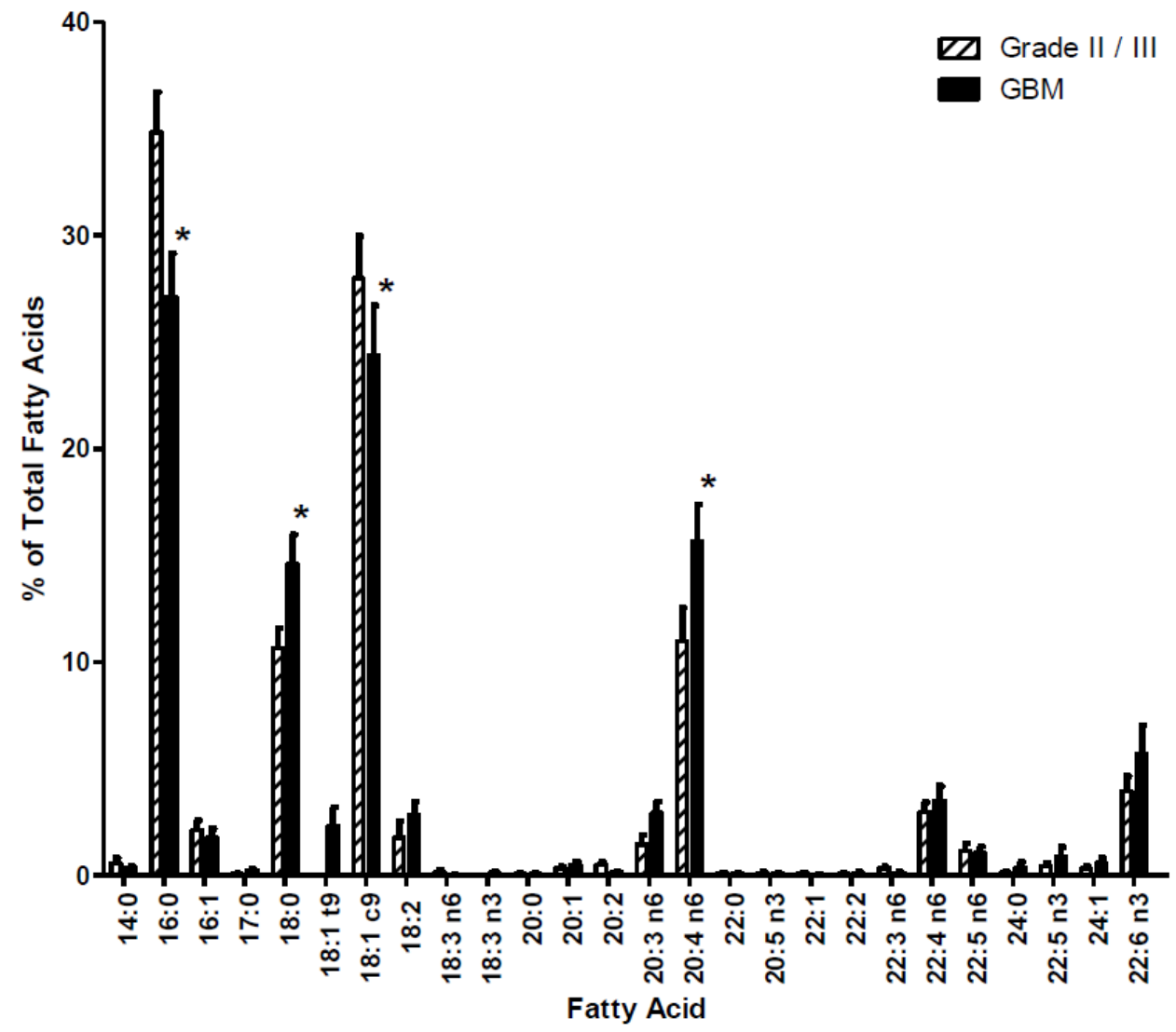

B

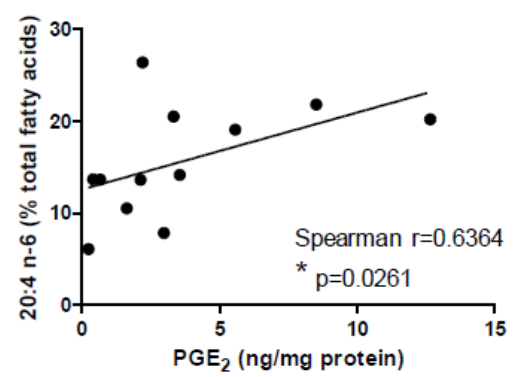

D

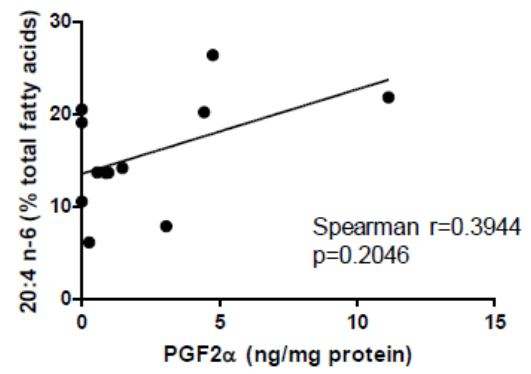

C

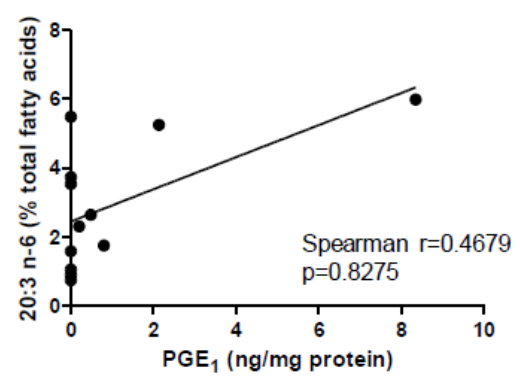

E

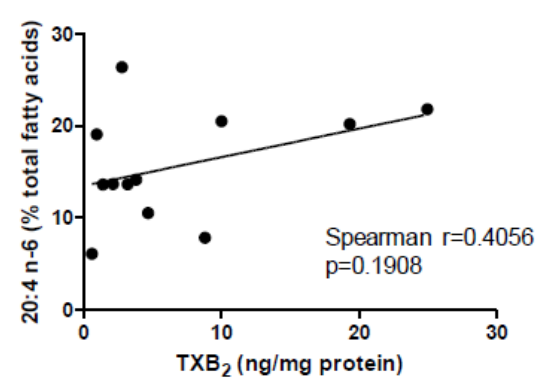


Fig. 5 Correlations between prostanoid concentrations and tumor grade
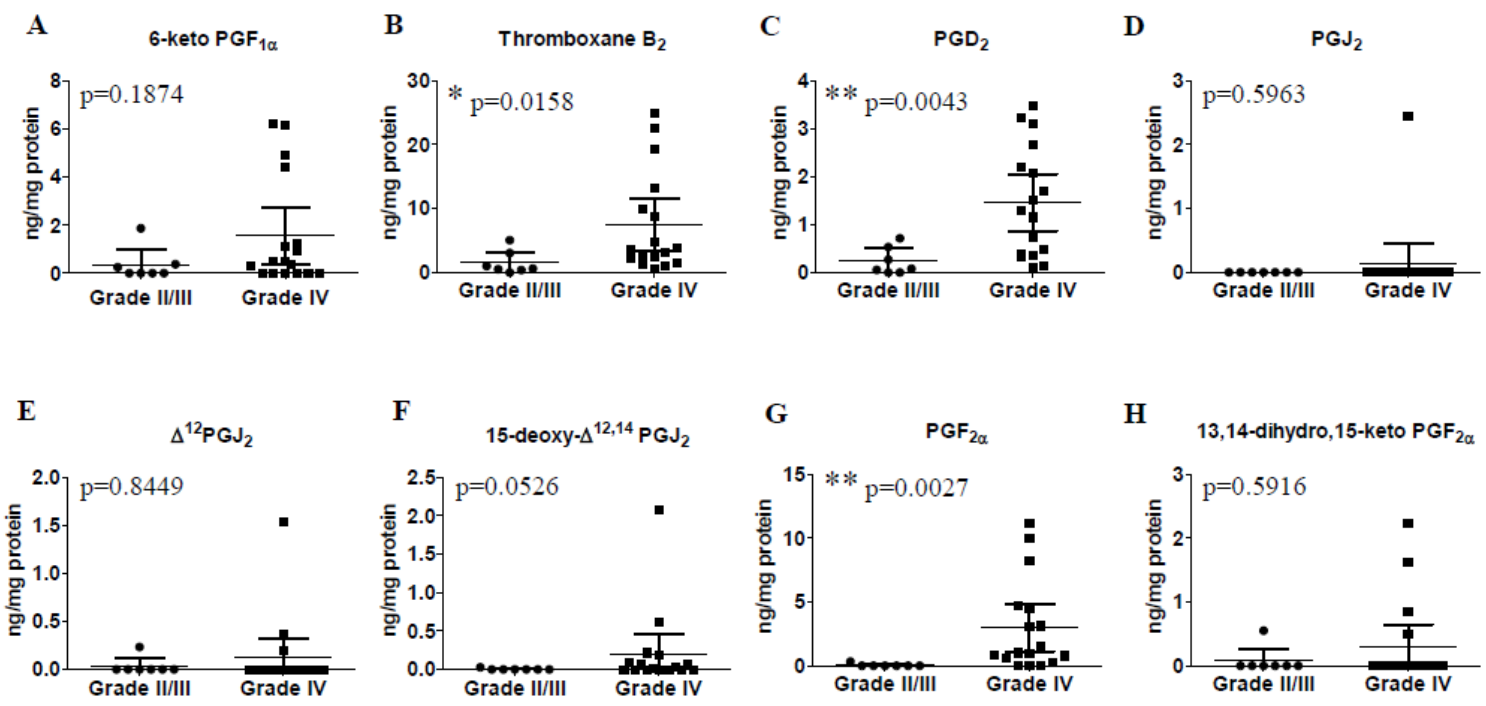

G

$\mathrm{PGF}_{2 \alpha}$

H 13,14-dihydro,15-keto $\mathrm{PGF}_{2 \alpha}$
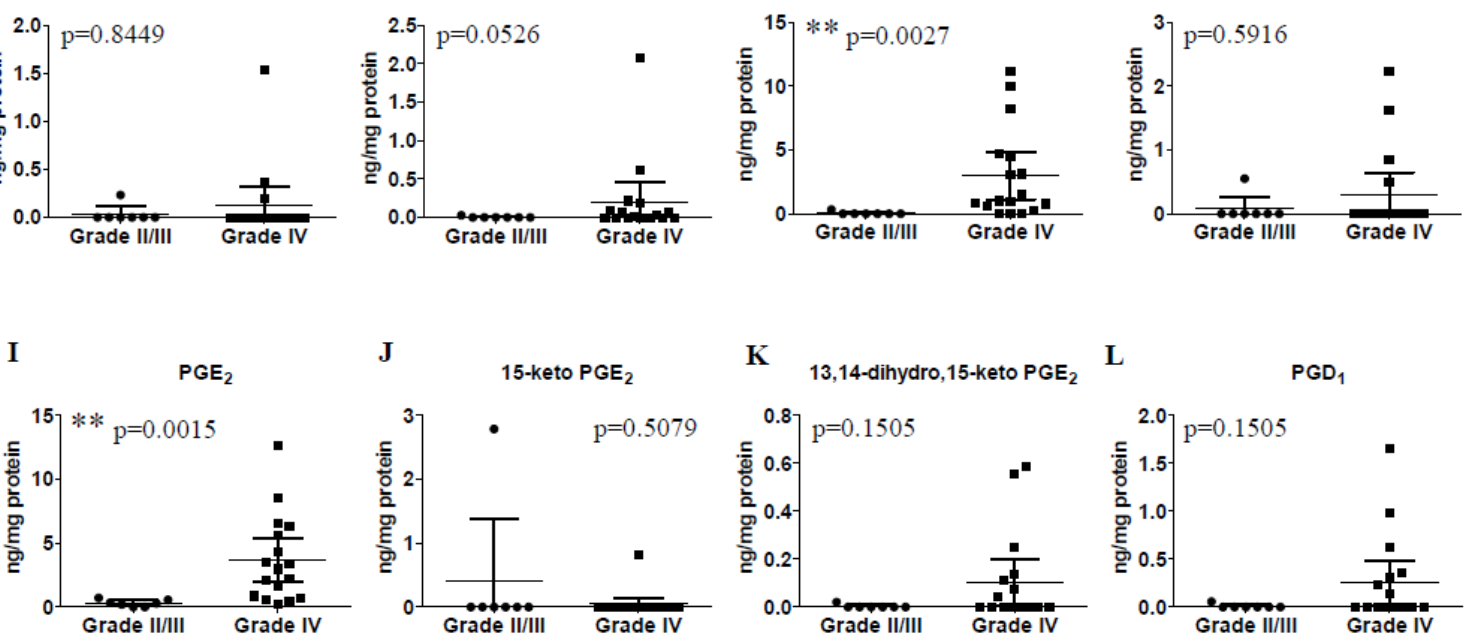

J 15-keto $\mathrm{PGE}_{2}$

K

13,14-dihydro,15-keto $\mathrm{PGE}_{2}$

L

$\mathrm{PGD}_{1}$
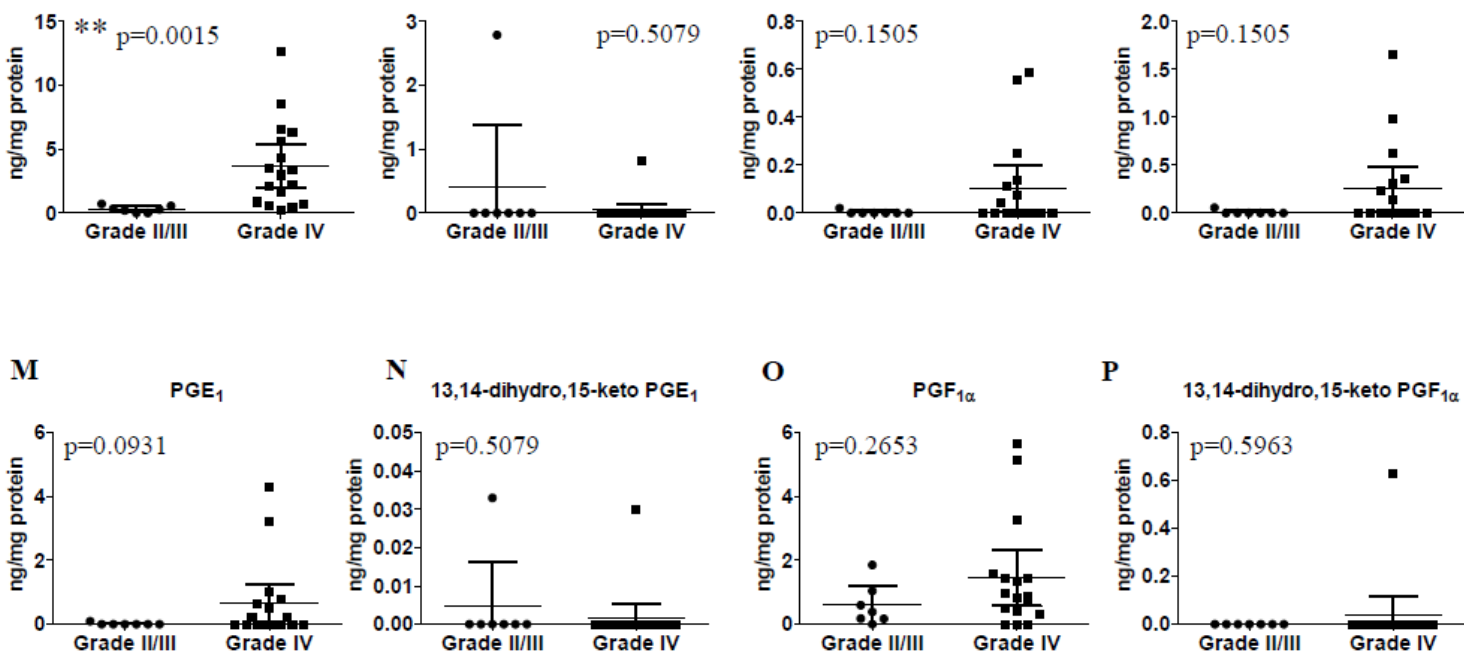

$\mathbf{P}$ 13,14-dihydro, 15-keto $\mathrm{PGF}_{1 \alpha}$

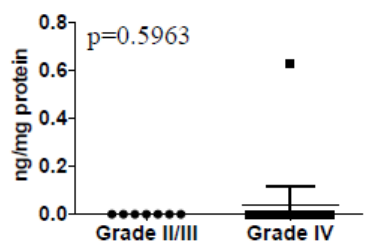


Fig. 6 Correlations between prostanoid concentrations and patient survival

A

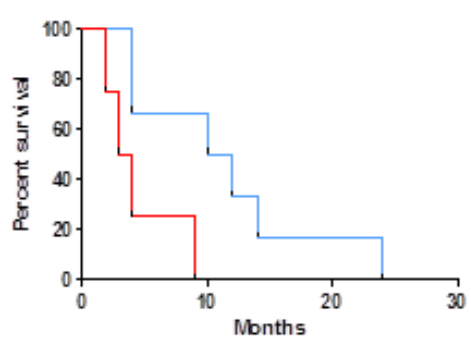

C

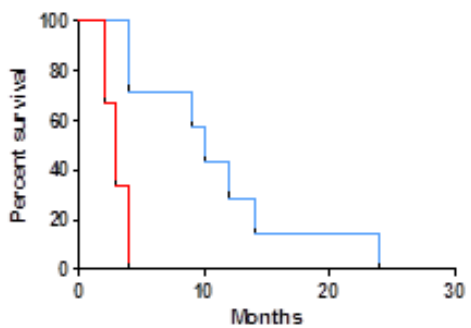

E

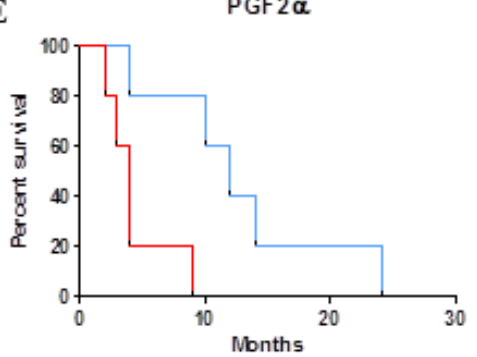

1. Low PGE:
+ High PGE:

* $p=0.0221$
+ LOW PGE + PGEME

1. High PGE + PGEMs

*t $p=0.0074$
D

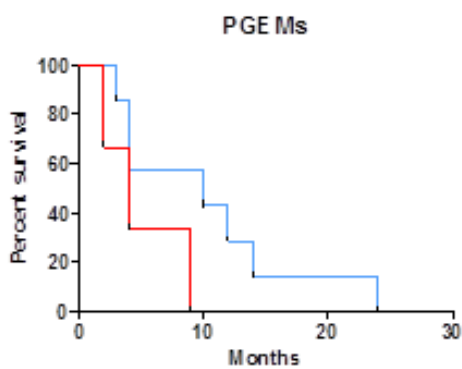

F

1. Low PGF
$\perp$ High PGF

${ }^{*} p=0.0112$
B 13,14-dihydro,15-keto $\mathrm{PGE}_{2}$

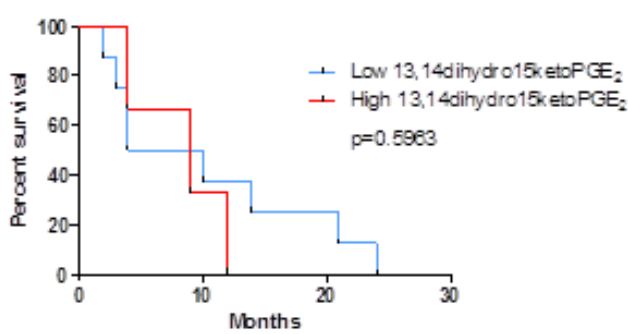

- High PGEMs $p=0.1160$

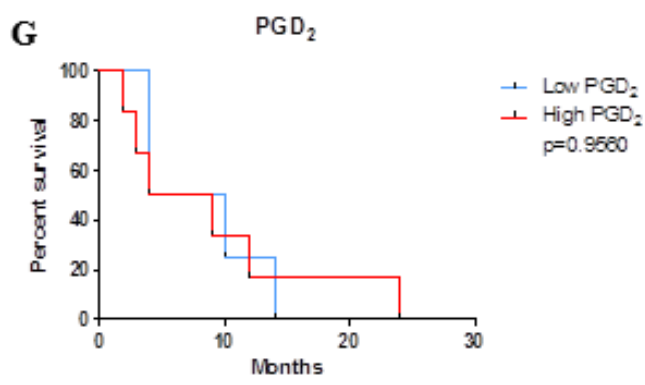

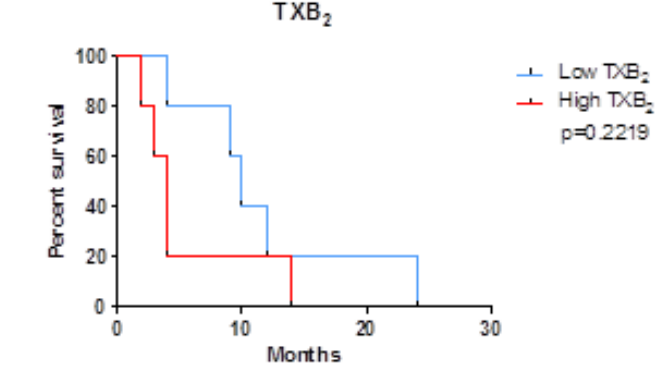


Suppl. Fig. 1 Variation in housekeeping reference genes among GBM patient samples

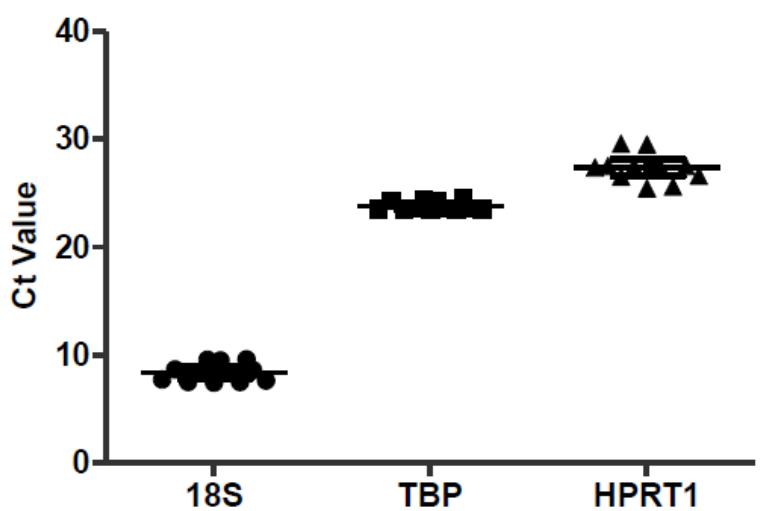

\begin{tabular}{|l|l|l|l|}
\hline Gene & $18 \mathrm{~S}$ & TBP & HPRT1 \\
\hline Mean Ct & 8.392 & 23.82 & 27.39 \\
\hline SEM & 0.2404 & 0.1299 & 0.3678 \\
\hline
\end{tabular}

$\mathrm{n}=12$, one way ANOVA with Tukey's post-test

$18 \mathrm{~S}$ vs TBP $\mathrm{p}<0.001$

$18 \mathrm{~S}$ vs HPRT1 $\mathrm{p}<0.001$

TBP vs HPRT $1 \mathrm{p}<0.001$ 
Suppl.Fig. 2 mRNA expression data versus patient survival for prostaglandin reductase 2 and 3
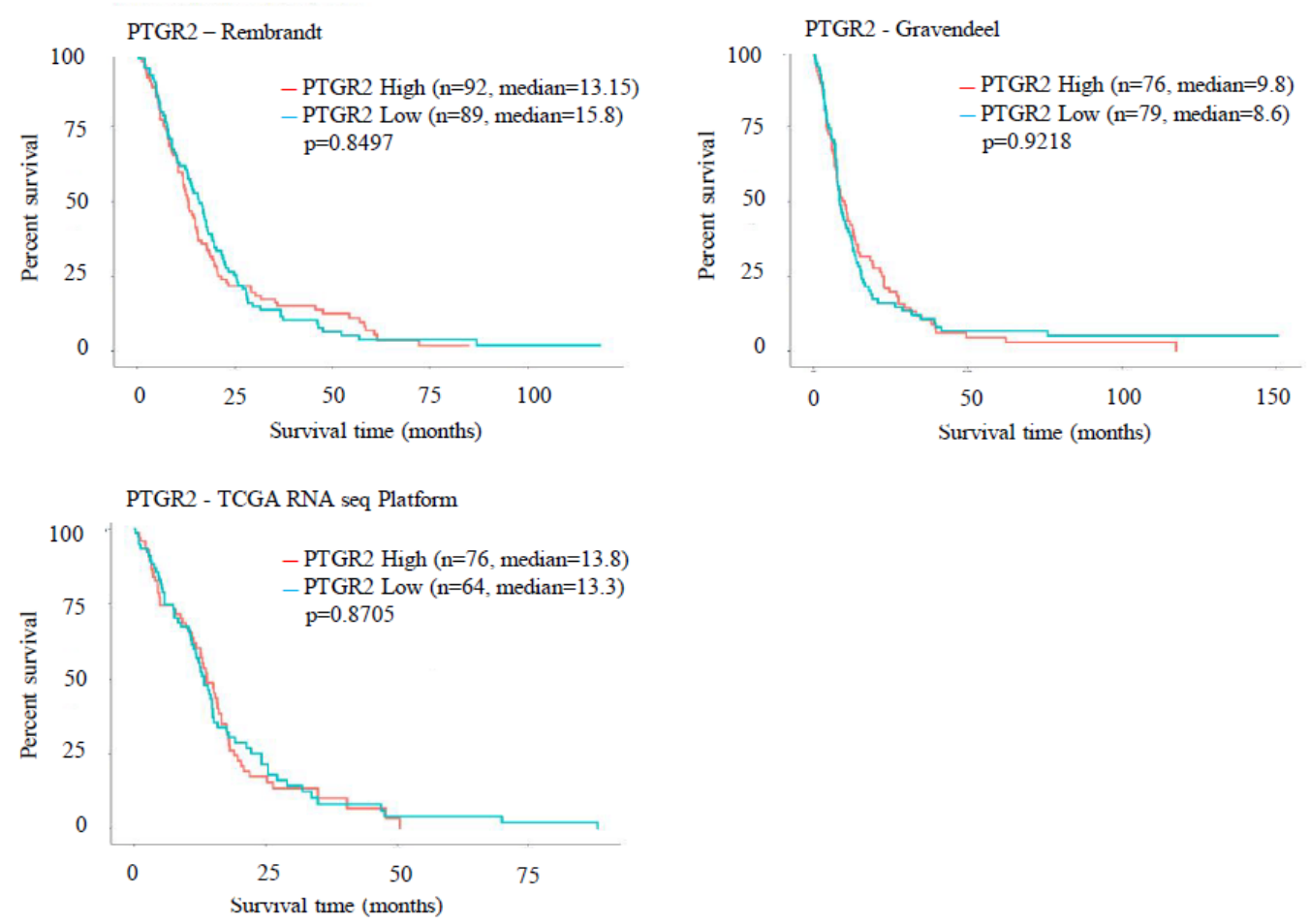

PTGR3 (ZADH2) - TCGA (A)
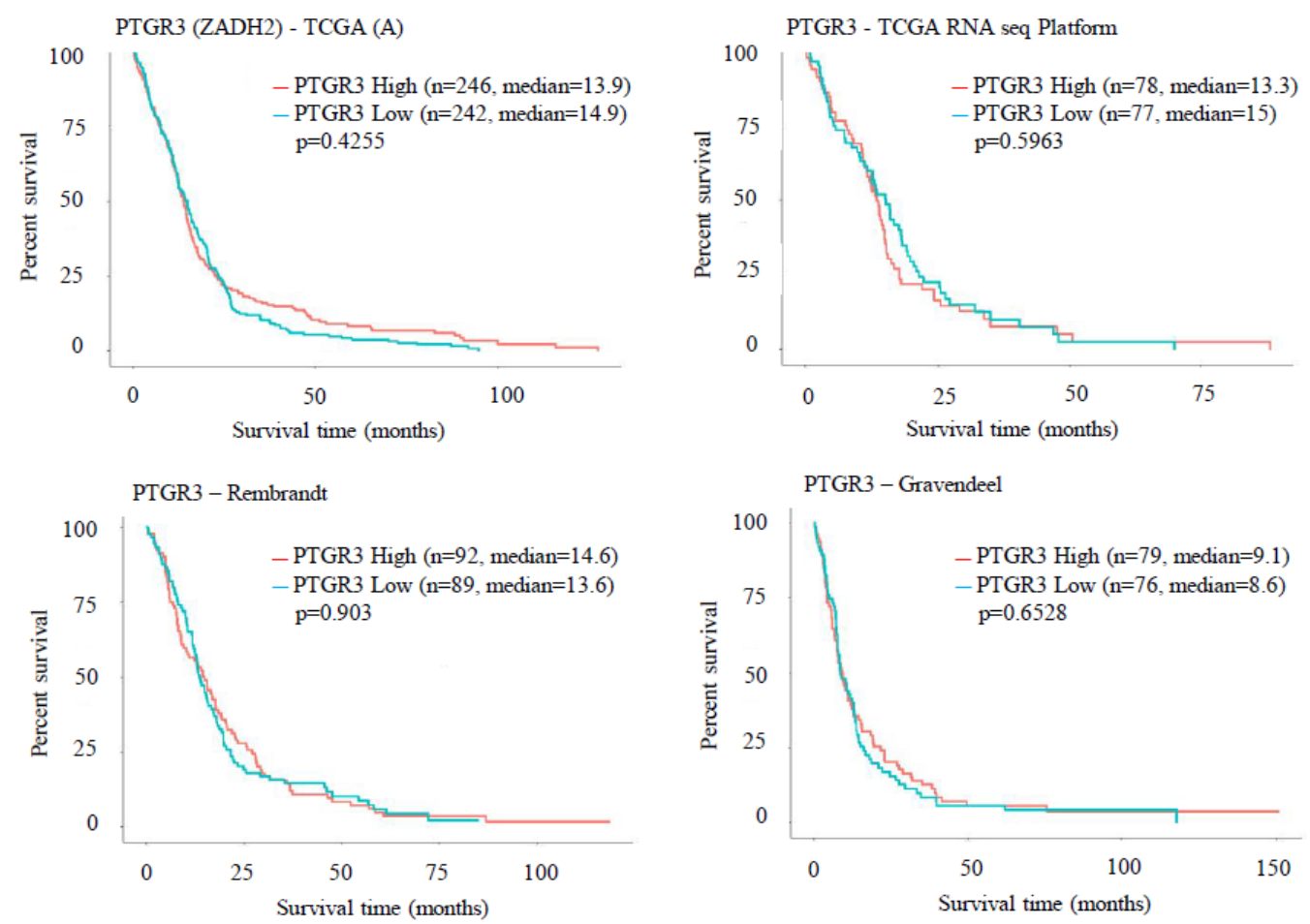